\title{
Evaporation of Alloying Elements and Behavior of Degassing Reactions of High Chromium Steel in Electron Beam Melting
}

\author{
Ryuji NAKAO, Shigeo FUKUMOTO, Masao FUJI" and Hidemaro TAKEUCHI \\ Hikari R \& D Laboratory, Nippon Steel Corporation, Shimata, Hikari, Yamaguchi-ken, 743 Japan. \\ 1) Technical Development Bureau, Nippon Steel Corporation, Shintomi, Futtsu, Chiba-ken, 299-12 Japan.
}

(Received on November 25, 1991; accepted in final form on February 28, 1992)

\begin{abstract}
Electron beam melting enables to evaporate the volatile alloying elements and remove carbon, oxygen and nitrogen by high-temperature, high-vacuum melting. A rod melting technique with $250 \mathrm{~kW}$ EB furnace was applied to stainless steel and high chromium steel.

Evaporation reaction of alloying elements during melting was of the first order and was considered to be rate-controlled by free evaporation. Rate of evaporation of alloying elements was higher for element with higher vapor pressure. Further the speed of evaporation was in proportion to the square root of melting energy of electron beam, and this relation was possible to be derived from Langmuir's equation. Deoxidation and decarburization reactions were enhanced by $\mathrm{CO}$ degassing reaction. The removal of nitrogen was remarkably enhanced with increasing amount of the $\mathrm{CO}$ degassing reaction, and removal ratio of higher than $30 \%$ was possible.

Based on the results above, controlling compositions of melted ingots was made possible, and achievement of high purification of $[\mathrm{O}]+[\mathrm{C}]+[\mathrm{N}] \leqq 50 \mathrm{ppm}$ in $25 \%$ chromium steel was made possible.
\end{abstract}

KEY WORDS: electron beam melting; stainless steel; high chromium steel; evaporation; purification; degassing.

\section{Introduction}

The electron beam melting (EB melting) process is characterized by a melting temperature of higher than $3000 \mathrm{~K}$ utilizing high energy density of electron beams and high vacuum of $10^{-1} \mathrm{~Pa}$ or less. The temperature and the atmosphere can not be achieved by any other melting techniques so that the melting of refractory metals such as niobium, tantalum, tungsten, or reactive metals such as titanium have been practiced in the EB melting furnace. ${ }^{1-3)}$

Recently, this melting technique has been applied for nickel base super alloy. However, there has not been reported its industrial applications to the stainless steel or the high chromium steel but those in laboratory scale because the evaporation losses of chromium and manganese or other volatile elements were serious and it was very difficult to maintain its chemical composition constant.

It is well known that when the melting energy and vapor pressure of species increased, the evaporation losses of those elements also increased. ${ }^{4)}$ However, since most of data reported was obtained for experiments in the small crucible or by the button melting process, ${ }^{4,5}$ ) these could not be a guide line for the industrial application where a water cooled continuous casting equipment should be applied. Elimination of gaseous species such as carbon, oxygen and nitrogen were observed but no further research work has not been reported yet.

In the present study, the quantitative analysis of reactions for evaporating of alloying elements in the steels containing volatile alloying elements such as manganese, copper and chromium was therefore studied in the industrial scale furnace of $250 \mathrm{~kW}$ by using the rod melting technique. Steels containing 17 to $55 \%$ chromium were also studied for removing carbon, oxygen and nitrogen.

Ingot properties were assessed after hot and cold rolling and annealing by the charpy impact test and pitting corrosion test.

\section{Experimental Apparatus and Procedure}

The $250 \mathrm{~kW}$ EB Remelting Furnace (EBR) used in this work was designed and produced by the Ardenne Research Institute and LEW (Lokomotivebau-Electrotechnishe Werke) in Germany. Figure $\mathbf{1}$ gives a schematic view of the melting apparatus. This furnace has one gun and is possible to carry out a crucible melting, a hearth melting and a rod melting, but in the present study, all experiments were carried out by the rod melting technique. Previously fused raw materials were fed alternately from either side of the beam in a horizontal direction. These feeding stocks were melted by the impingement of the electron beam and subsequently fell 
into the water cooled crystallizer. The electron beam would impinge alternately on the solid feeding material and on the molten metal below to maintain a molten pool in the crystallizer. The solidified ingot lower in the crystallizer was then withdrawn intermittently from beneath.

The chemical compositions of raw materials and experimental conditions are listed in Tables 1 and 2. The grades of stainless steels SUS 316, 304 and high chromium steel were employed in the melting test. Manganese, copper, chromium and nitrogen content varied within the ranges indicated since evaporation rates and the oxygen per carbon ratio were not constant. Raw materials were produced in a $150 \mathrm{~kg}$ vacuum induction melting furnace (VIM) then cast into ingot. Ingots were hot forged into square billets of 100 and $150 \mathrm{~mm}$ cross section.

To investigate the effect of melting condition on the refining and evaporation of alloying elements, the crystallizer size, melting power and melting speed were varied as indicated. Although a vacuum of $1 \times 10^{-2} \mathrm{~Pa}$ was sought, actual values ranged between $0.5 \times 10^{-2}$ and
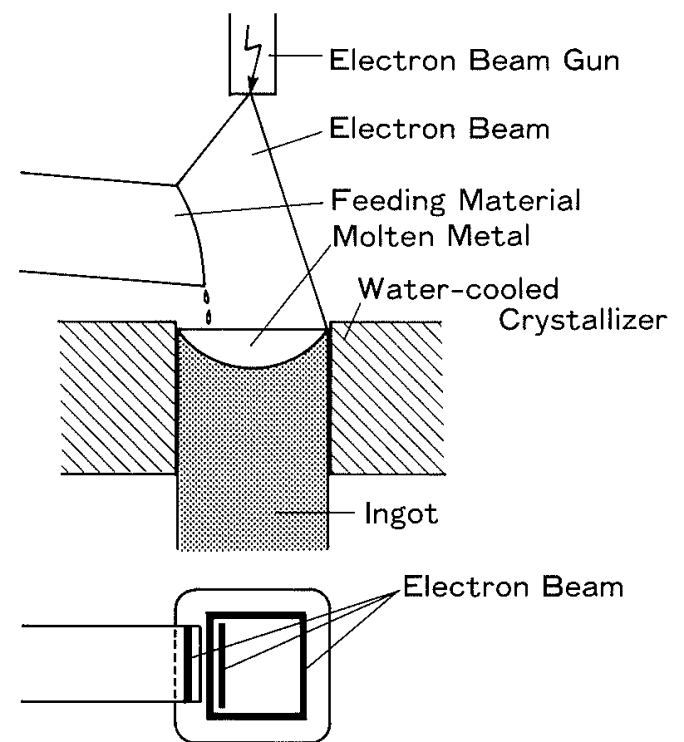

Fig. 1. Schematic view of the EB melting process.

Table 1. Experimental conditions.

\begin{tabular}{lc}
\hline \multicolumn{1}{c}{ Item } & Condition \\
\hline Crystallizer & $305 \times 61,157 \phi, 177 \phi, 305 \mathrm{~mm} \phi$ \\
Supplied EB power & $80-200 \mathrm{~kW}$ \\
Feeding Size $\quad$ Rate & $100,150 \mathrm{~mm} \phi$ \\
Speed of withdrawing & $0.008-0.05 \mathrm{~kg} / \mathrm{sec}$ \\
Pressure level & $0.05-0.2 \mathrm{~mm} / \mathrm{sec}$ \\
\end{tabular}

$10.0 \times 10^{-2} \mathrm{~Pa}$ due to variations in raw materials and the vacuum system.

In this melting process, sampling from the molten pool during EB melting was impossible, so samples for chemical analyses were prepared from the feeding materials and EB melted ingots. Amount of evaporation were calculated from the difference in chemical compositions of the feeding materials and EB melted ingots. In some experiment, evaporation deposit which was deposited in the melting chamber was sampled for measuring the absolute amount of evaporated elements.

\section{Behaviors of Evaporation Reaction of Alloying Elements}

Figure 2 shows the compositions of feeding materials, vapor deposits on inside wall of the melting chamber (A, B), deposits on upper surface of crystallizer (C, D) after melting and EB melted ingot. The relative amounts of manganese, copper and chromium evaporated by EB melting are quite large, while those of silicon, sulfur and nickel are much lower by comparison. Based on these results, evaporation losses were calculated using nickel as a reference. It was assumed that nickel loss was negligible.

In Fig. 3, the relation between melting time and contents of manganese, copper and chromium are plotted logarithimically, when supplied electron beam powers were held constant and melting speeds were changed. Here, melting time means the holding time of molten state assumed that the volume of molten pool is constant $\left(1.1 \times 10^{6} \mathrm{~mm}^{3}\right)$ for respective conditions. As expected, the evaporation of alloying elements having higher vapor

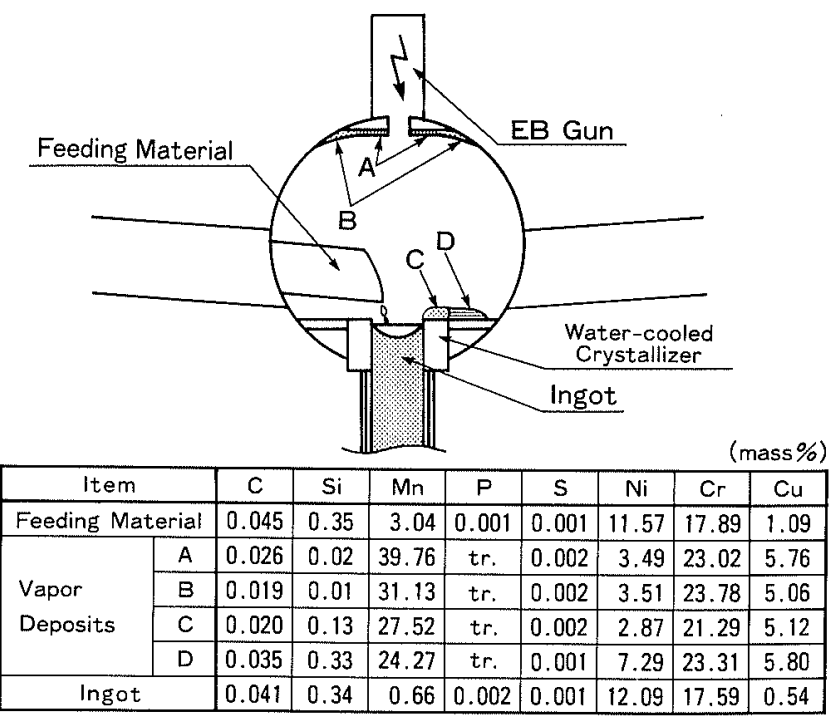

Fig. 2. Composition of feeding material and vapor deposits during EB melting.

Table 2. Chemical composition of raw materials. (mass $\%$ )

\begin{tabular}{lcccccccccc}
\multicolumn{1}{c}{ Grade } & $\mathrm{C}$ & $\mathrm{Si}$ & $\mathrm{Mn}$ & $\mathrm{Ni}$ & $\mathrm{Cr}$ & $\mathrm{Mo}$ & $\mathrm{Cu}$ & $\mathrm{O}$ & & \\
\hline SUS316 & 0.04 & 0.3 & $1.0-12.0$ & $10.0-12.0$ & $17.0-20.0$ & $2.0-2.5$ & $0.1-2.5$ & $0.003-0.02$ & $0.02-0.08$ \\
SUS304 & 0.05 & 0.5 & $2.0-6.0$ & $8.0-9.0$ & $17.0-20.0$ & tr. & $0.1-2.5$ & $0.003-0.01$ & $0.02-0.06$ \\
High chromium steel & $0.005-0.05$ & tr. & tr. & tr. & $17.5-55.0$ & tr. & tr. & $0.005-0.05$ & $0.002-0.01$ \\
\hline
\end{tabular}




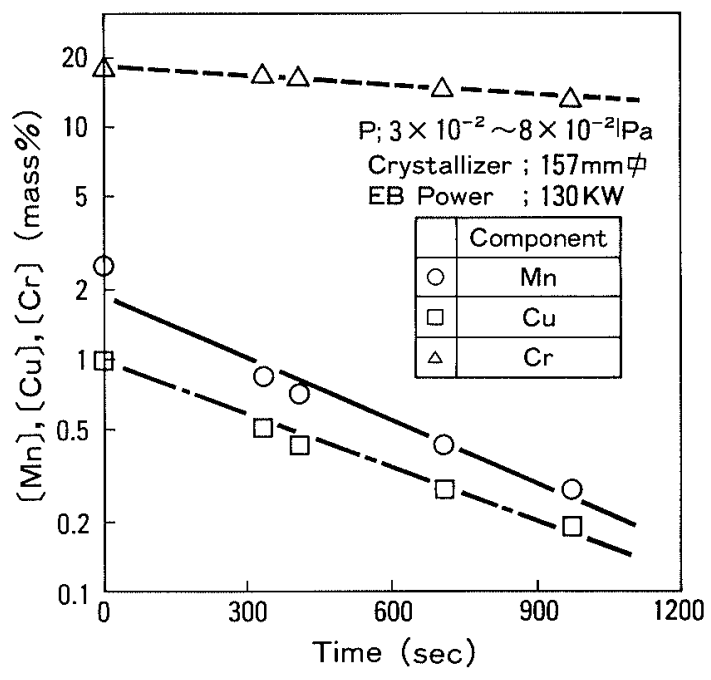

Fig. 3. Relation between melting time and contents of manganese, copper and chromium.

pressures (i.e. $\mathrm{Mn}>\mathrm{Cu}>\mathrm{Cr}$ ) was large, and evaporation reaction of elements was found to be possible to express by first order reaction as Eq. (1).

$$
-\frac{d C_{i}}{d t}=k \frac{A}{V} C_{i}
$$

where, $C_{i}$ is the content of evaporated component $i, t$ is the melting time, $k$ is the evaporation reaction constant, $A$ is the area of reaction interface and $V$ is the volume of molten metal.

For the reaction process of the evaporation loss, the following five steps should be considered:

1) transport of an atom through the melt to the neighborhood of the free metal surface,

2) transport across a boundary layer to the free metal surface,

3) desorption from the free metal surface into the gas phase,

4) transport across a boundary layer on the gas side of the free metal surface, and

5) transport through the gas to condensing site and condensation.

In this experimental condition, the surface temperature which was out of beam irradiation was so high as more than $1873 \mathrm{~K}$, and the degree of vacuum in the melting chamber was so low as less than $1.0 \times 10^{-1} \mathrm{~Pa}$. In the melting unit used, the melt was in rapid movement caused by convective stirring, and convective stirring occurred in the gas phase, so that steps 1) and 5) were unlikely to be rate limiting step. We therefore should consider steps 2)-4).

Figure 4 shows the relation between pressure level in the melting chamber and evaporation ratio of alloying elements under the constant condition of melting energy of $4.6 \times 10^{3} \mathrm{~kJ} / \mathrm{kg}$. EB Melting energy was calculated by dividing electron beam power by the melting rate of raw materials from the following equation:

$$
E=P / V
$$

where, $E$ is melting energy in $\mathrm{kJ} / \mathrm{kg}, P$ is supplied EB power in $\mathrm{kW}$, and $V$ is the melting rate in $\mathrm{kg} / \mathrm{sec}$.

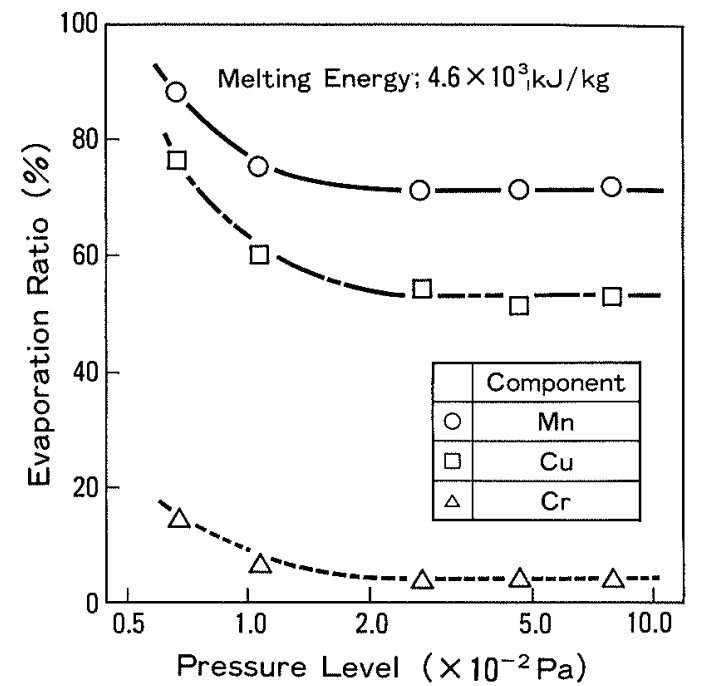

Fig. 4. Effect of pressure level in melting chamber on evaporation ratio.

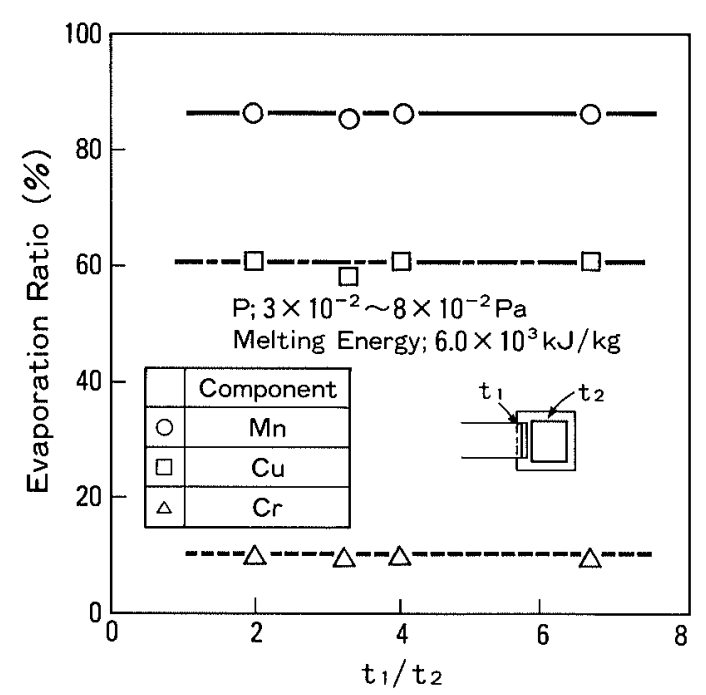

Fig. 5. Effect of sharing time of $\mathrm{EB}$ on evaporation ratio.

In low pressure side less than $2.0 \times 10^{-2} \mathrm{~Pa}$, evaporation ratio showed the tendency of decrease as the rise of pressure level, and in high pressure side, that showed constant value with no regard to the pressure level. Accordingly, in low pressure less than $2.0 \times 10^{-2} \mathrm{~Pa}$, the step 4) was assumed to be a possible rate limiting step. In this study, experiments were generally carried out in the range of $2.0 \times 10^{-2}-8.0 \times 10^{-2} \mathrm{~Pa}$. In this range, evaporation rate was constant with no regard to the pressure level, so the influence of step 4) was supposed to be small.

The relations between the ratio $\left(t_{1} / t_{2}\right)$ which is divided beam irradiation time to the feeding material $\left(t_{1}\right)$ by beam irradiation time into the crystallizer $\left(t_{2}\right)$ and evaporation ratio of alloying elements is shown in Fig. 5. It appeared that evaporation ratios of manganese, copper and chromium were constant values with no regard to the time ratio.

Figure 6 shows the effect of supplied EB power on evaporation ratio of alloying elements when melting rate were the same. All of evaporation ratios of manganese, copper and chromium increased linearly with the increase 


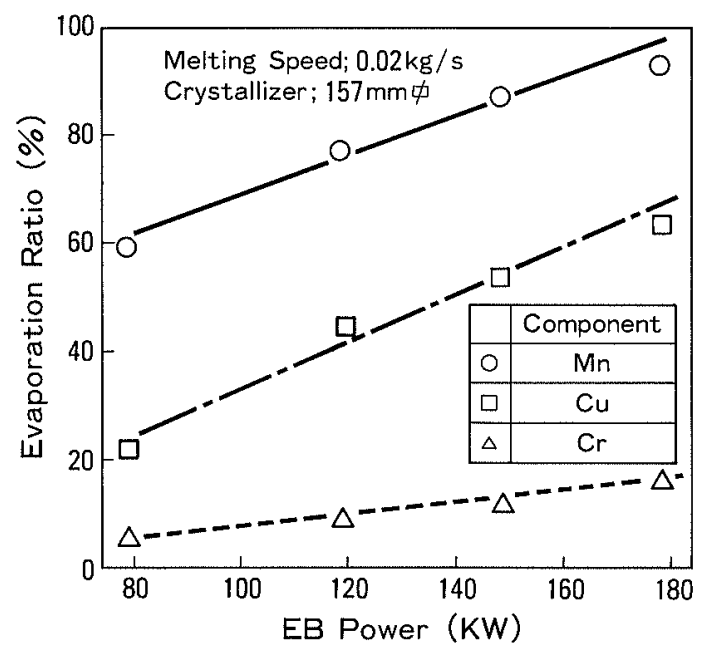

Fig. 6. Effect of EB power on evaporation ratio.

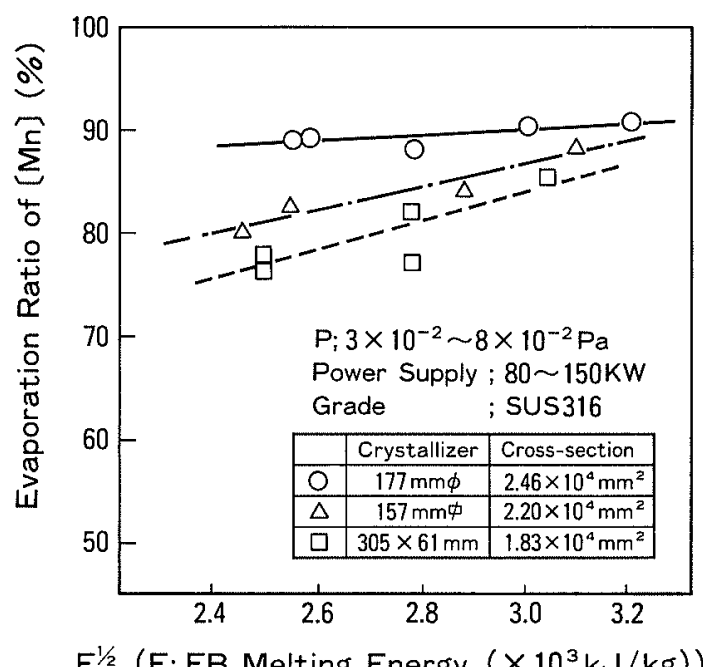

Fig. 7. Effect of melting energy on manganese evaporation losses using three different crystallizer configurations.

of supplied power.

The effect of EB melting energy on manganese evaporation losses using three different crystallizers is shown in Fig. 7. Evaporation ratio increased as the increase of melting energy and was proportional to the cross sectional area of the crystallizer.

From results of Figs. 5, 6 and 7 in EB melting, evaporation reaction is thought to occur on the surface of feeding material and molten pool which were impinged by electron beam, and amount of evaporation increase by rising of power supply, namely rise of the surface temperature and increasing of surface area. Based on these results, in the region of pressure level less than $2.0 \times 10^{-2} \mathrm{~Pa}$, step 3 ) is supposed to be a possible rate limiting step.

Figure 8 is a plot of the relative weight loss of alloying elements as a function of the square root of EB energy. Evaporation ratios were proportional to the square root of melting energy as calculated from the EB power and the feeding rate of raw material.

The relation between the square root of EB energy and evaporation rate of alloying elements when the same feeding material and the same crystallizer were used, is

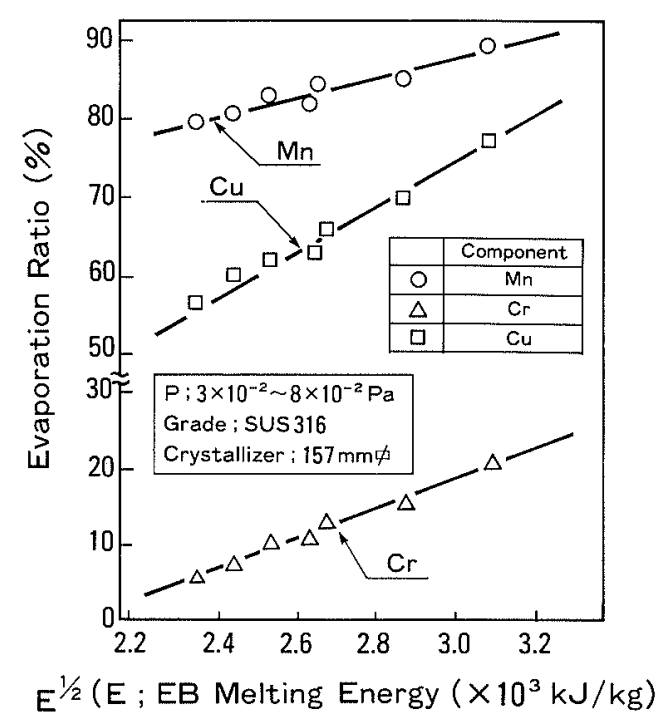

Fig. 8. Effect of melting energy on evaporation losses.

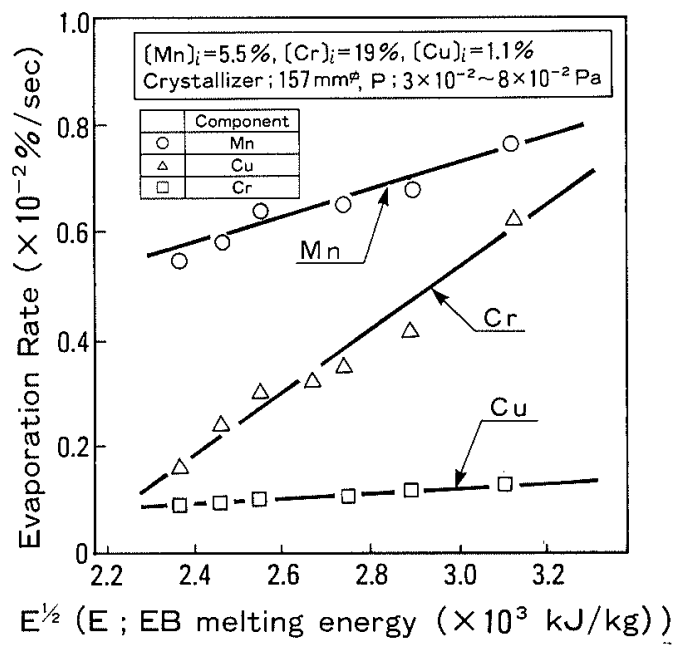

Fig. 9. Effect of EB melting energy on evaporation rates.

shown in Fig. 9. The value of evaporation rate was obtained by dividing the difference of compositions between feeding material and melted ingot by holding time of melting which was converted from the volume of molten pool. Evaporation rates of manganese, copper and chromium increase in proportion to the square root of melting energy. Here, evaporation rate of chromium was larger than that of copper. This was caused by the fact that chromium content in feeding material was more than 10 times compared to copper.

Based on above results, evaporation ratio and evaporation rate of alloying elements were found to be in proportional to the square root of EB melting energy. This can be explained as follows:

In general, the evaporation rate of alloying elements can be described by the Langmuir's equation. ${ }^{7)}$

$$
W_{i}=P_{i}\left(M_{i} / 2 \pi R T\right)^{1 / 2}
$$

where, $W_{i}$ is the evaporation rate of component $i, P_{i}$ is the partial pressure, $M_{i}$ is the moluculer weight, $R$ is gas constant and $T$ is the temperature.

The vapor pressure of component $i ; P_{i}$, is related to the alloy composition by Raoul't Law at a constant 
temperature.

$$
P_{i}=P_{i}^{\circ} \gamma_{i} N_{i}
$$

where, $P_{i}^{\circ}$ is the vapor pressure of component $i, \gamma_{i}$ is the activity coefficient and $N_{i}$ is the mole fraction.

In this study, the mean temperature of the molten pool surface was in the range of $1873-2023 \mathrm{~K}$, so $P_{i}^{\circ}$ is supposed to be proportional to $T$ if the effect of alloying elements is neglected. When the feeding material with same composition is melted, Eq. (5) is assumed.

$$
P_{i}=k_{5} T
$$

where, $k_{5}$ is a proportionality constant

In the range of EB melting energy in $5.0 \times 10^{3}-10.0 \times$ $10^{3} \mathrm{~kJ} / \mathrm{kg}$ of present study, the temperature of the molten pool surface had a tendency of rising as increasing of EB melting energy. So the following expression is assumed.

$$
T=k_{6} E
$$

where, $k_{6}$ is a proportionality constant.

Substituting (4)-(6) to Eq. (3), Eq. (7) is possible.

$$
W_{i}=k_{7} E^{1 / 2}
$$

where, $k_{7}$ is a proportionality constant.

Therefore, in the case when the melting was carried out using feeding material with same composition, the evaporation of alloying elements was proportional to the square root of EB melting energy as shown in Fig. 9. In the case when the feeding materials with different composition were used, the evaporation ratio may be used instead of evaporation rate.

In the range of pressure level higher than $2.0 \times 10^{-2} \mathrm{~Pa}$, using these relationships it was possible to control the chemical composition of stainless steels by adjusting feeding material chemistry and EB melting energy.

\section{Decarburization, Deoxidation and Denitrization of High Chromium Steel}

In EB melting process, melting is carried out under high temperature and high vacuum, so removal of gaseous elements such as carbon, oxygen and nitrogen can be expected. Investigation for the behavior of degassing reaction during $\mathrm{EB}$ melting was therefore applied using $\mathrm{Fe}-17-55 \% \mathrm{Cr}$ alloy.

Figure 10 illustrates the relation between carbon content and oxygen content before and after EB melting. In addition, the equilibrium values which was obtained by equilibrium equation of $\mathrm{CO}$ degassing reaction, ${ }^{8)}$ are plotted. This relation was not affected by the chromium content, but related directly to the amount of carbon and oxygen consumed in the $\mathrm{CO}$ degassing reaction. It may be assumed that all of the decarburization and deoxidation which takes place at this high temperature and high vacuum is due to the $\mathrm{CO}$ reaction.

Figure 11 shows the relationship between the oxygen over carbon ratio in raw materials and the total amount of carbon and oxygen contents in ingots. With an increase in the oxygen over carbon ratio, oxygen content rose and carbon content fell. When the ratio was adjusted to

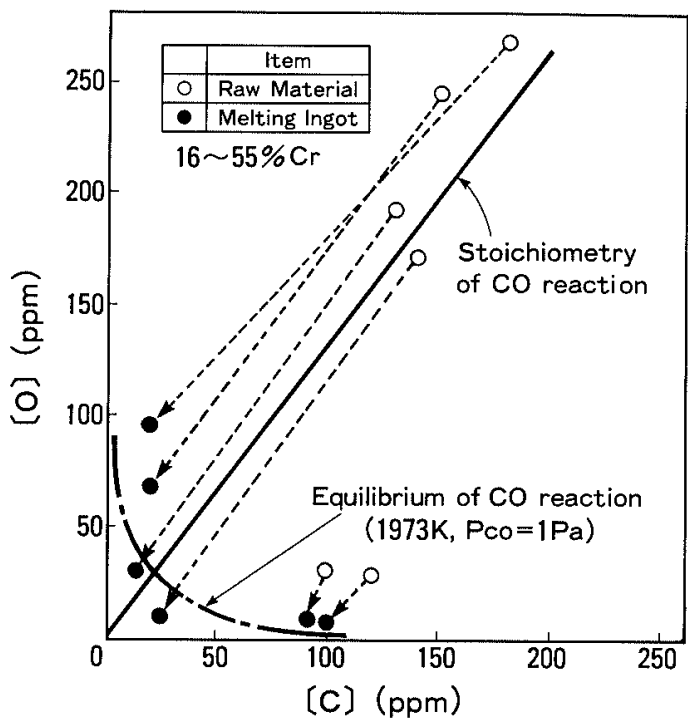

Fig. 10. Relation between carbon and oxygen content during EB melting.

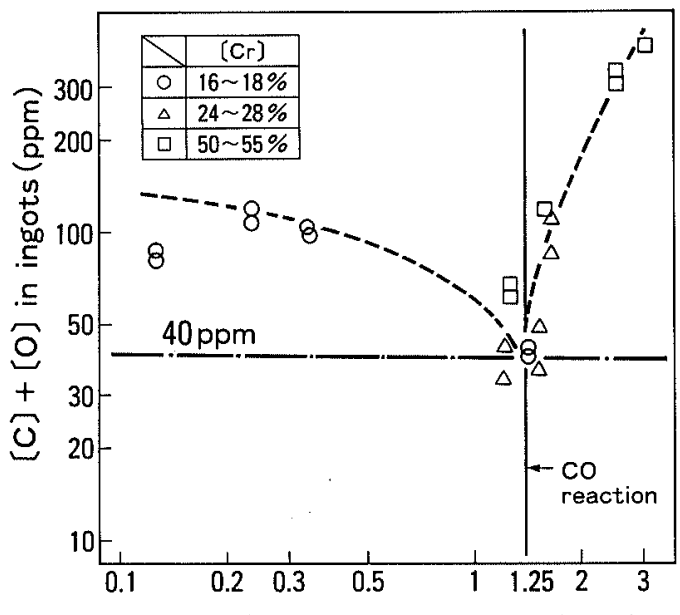

$[0] /[C]$ in raw materials (ppm)

Fig. 11. Relationship between the $[\mathrm{O}] /[\mathrm{C}]$ ratio in raw materials and total $[\mathrm{C}]+[\mathrm{O}]$ in the remelted products.

1.25 , total oxygen and carbon content was reduced to a minimum, and high purity steel was produced. For example total oxygen and carbon content for $25 \% \mathrm{Cr}$ alloy was less than $40 \mathrm{ppm}$. 1.25 was close to the 1.33 carbon to oxygen ratio in $\mathrm{CO}$ gas. This verified the assumption that decarburization and deoxidation occurred solely as a result of the $\mathrm{CO}$ degassing reaction.

The effect of EB melting energy on oxygen content in ingots when oxygen over carbon ratio in raw materials are in the range of 1.0-1.5 is shown in Fig. 12. Oxygen content was not depending on melting energy, and nearly constant level was kept. Oxygen content of less than 20 ppm was attainable if oxygen over carbon ratio in raw material was properly adjusted. It may be assumed that $\mathrm{CO}$ reaction is reached to equilibrium apparently, and as shown in Fig. 10, $P_{\mathrm{CO}}$ level is in the range of $10^{-1}$ to $10^{0} \mathrm{~Pa}$ which is corresponding to $10^{1}-10^{2}$ times of pressure level in the melting chamber $\left(10^{-1}-10^{-2} \mathrm{~Pa}\right)$. This may be explained that the partial pressure of $\mathrm{CO}$ in the molten pool surface was higher than that in the 


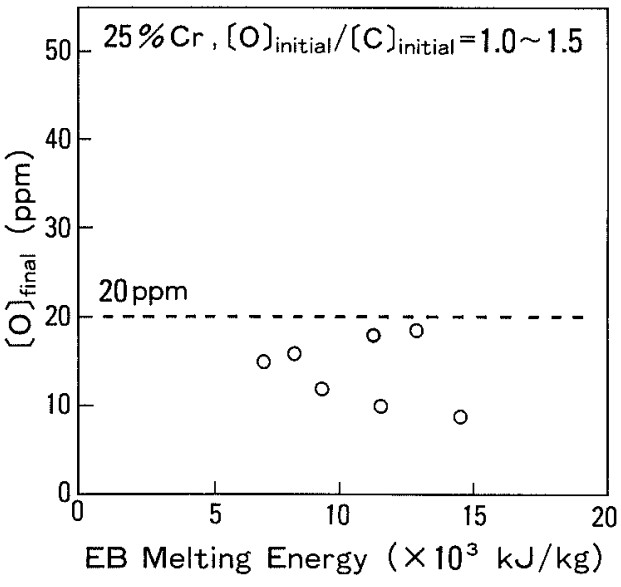

Fig. 12. Effect of melting energy on deoxidation reaction.

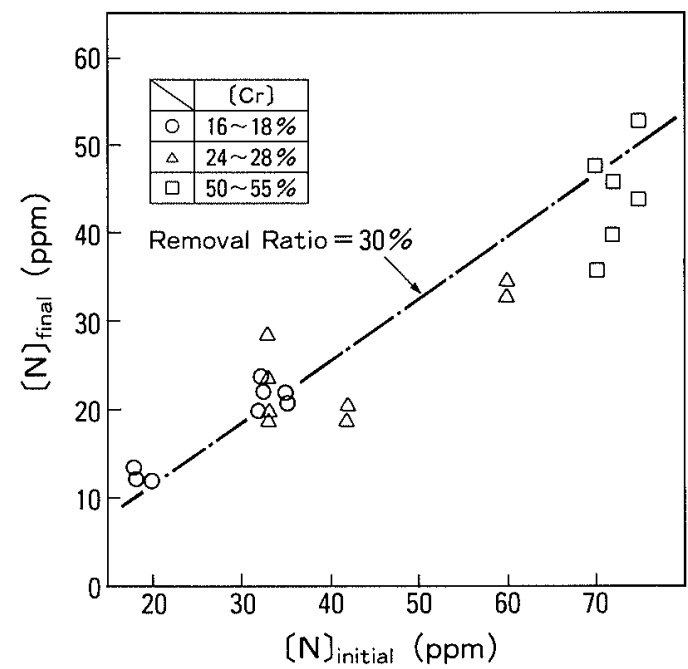

Fig. 13. Relation between initial and final content of nitrogen.

melting chamber because $\mathrm{CO}$ gas was generated in the pool surface, or the partial pressure of $\mathrm{CO}$ became higher by the evaporation of alloying elements.

In Fig. 13, the relation of nitrogen contents before and after EB melting is shown. The nitrogen content in EB melted ingot was higher, when the nitrogen content in raw material was higher. Further, the denitrization ratio was in the range of 20 to $50 \%$ with no regard to chromium content.

Figure 14 shows the relation between the reduction of carbon content $(\Delta[C])$ and the reduction of nitrogen content $(\Delta[\mathrm{N}])$ during EB melting. $\Delta[\mathrm{N}]$ increased as $\Delta[\mathrm{C}]$ increasing independent on chromium content. The magnitude of $\Delta[\mathrm{C}]$ referred to the amount of $\underline{\mathrm{C}}+\underline{\mathrm{O}}=$ $\mathrm{CO}(\mathrm{g})$ reaction, and the amount of $\mathrm{CO}$ gas generated increased as $\Delta[\mathrm{C}]$ increasing. Accordingly, it may be concluded that the denitrization reaction is controlled by the diffusion of nitrogen in metal or interfacial chemical reaction in EB melting. The denitrization reaction is therefore supposed to accelerated by enhancing convection in the metal bath or convection in metal-gas interface owing to increase $\mathrm{CO}$ gas generation.

The reaction between chromium content and nitrogen content in EB melted ingots is shown in Fig. 15 along with the thermodynamic equilibrium as calculated from

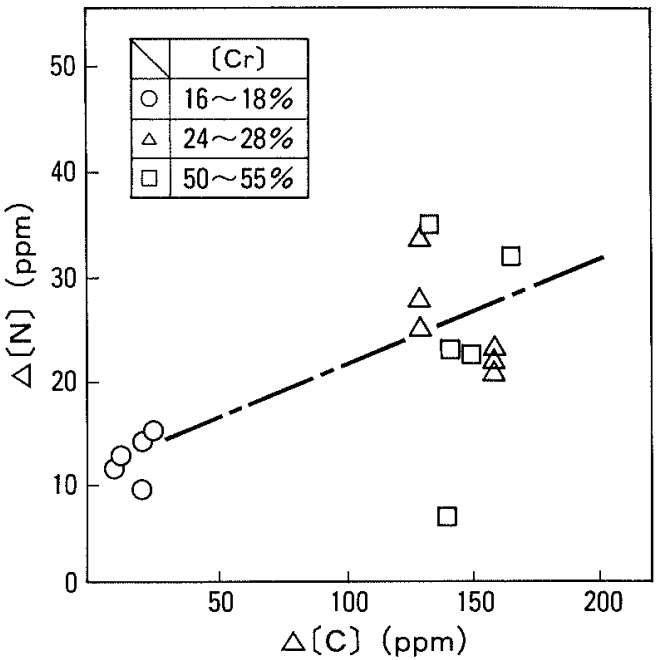

Fig. 14. Relation between reduction of carbon and nitrogen content during EB melting.

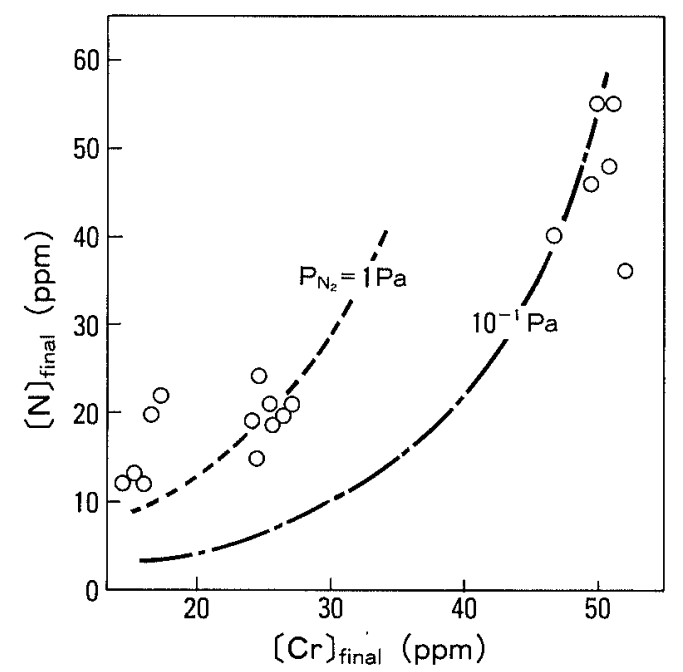

Fig. 15. Relation between chromium and nitrogen content of EB melted ingots.

Eq. (8) which was obtained by Fuwa et al. ${ }^{9}$

$$
\log [\% \mathrm{~N}]=0.5 \log P_{\mathrm{N}_{2}}-\log f_{\mathrm{N}}-399 / T-1.12
$$

where, $f_{\mathrm{N}}$ is the activity coefficient of nitrogen and this value was calculated from "Steelmaking Data Source Book" by the Japan Society for Promotion of Science. ${ }^{8)}$

Nitrogen content became higher as chromium content went higher, and $P_{\mathrm{N}_{2}}$ was in the range of $10^{-1}$ to $10^{1} \mathrm{~Pa}$ which was corresponding to $10^{1}-10^{3}$ times of pressure level in melting chamber $\left(10^{-1}-10^{-2} \mathrm{~Pa}\right)$.

Under the melting condition, denitrization reaction is not likely reached to equilibrium. It may be necessary to reduce the nitrogen content in raw material and secure the amount of $\mathrm{CO}$ reaction by increasing the carbon and oxygen contents in raw material in order to reduce the nitrogen content in EB melted ingot.

In this experiment, pressure level of the melting chamber was still in the range of $10^{-1}$ to $10^{-2} \mathrm{~Pa}$, and the influence of pressure level on decarburization, deoxidation and denitrization reactions were not observed. 
Table 3. Chemical composition of EB melting ingots.

\begin{tabular}{|c|c|c|c|c|c|c|}
\hline \multirow{2}{*}{ Melting method } & \multicolumn{4}{|c|}{ Composition (mass\%) } & \multirow{2}{*}{$\begin{array}{l}\mathrm{C}+\mathrm{N} \\
(\mathrm{ppm})\end{array}$} & \multirow{2}{*}{$\begin{array}{c}\mathrm{C}+\mathrm{N}+\mathrm{O} \\
(\mathrm{ppm})\end{array}$} \\
\hline & $\mathrm{Cr}$ & $\mathrm{O}$ & $\mathrm{C}$ & $\mathrm{N}$ & & \\
\hline \multirow{3}{*}{ EB melting } & 16.0 & 0.0009 & 0.0012 & 0.0012 & 24 & 33 \\
\hline & 24.7 & 0.0019 & 0.0009 & 0.0015 & 24 & 43 \\
\hline & 48.9 & 0.0037 & 0.0024 & 0.0049 & 73 & 110 \\
\hline $\begin{array}{l}\text { Vacuum induction melting } \\
\text { (VIM) }\end{array}$ & 24.0 & 0.0072 & 0.0030 & 0.0017 & 47 & 119 \\
\hline SS-VOD ${ }^{10)}$ & 26.0 & - & 0.0015 & 0.0050 & 65 & - \\
\hline
\end{tabular}

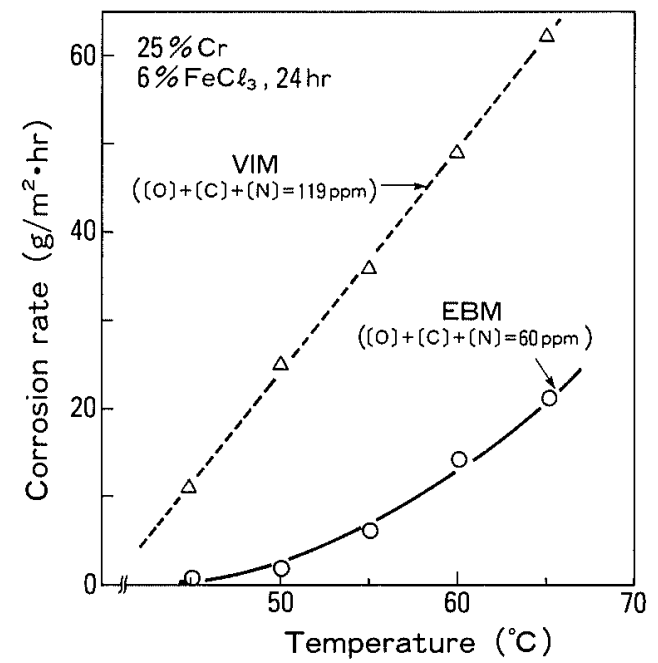

Fig. 16. Pitting corrosion results for $25 \% \mathrm{Cr}$ steel.

\section{Evaluation of Achieved Values by High Purification and Properties of EB Melted Products}

Table 3 lists the chemical compositions of EB melted ingots in this work in comparison with that of a VIM ingot and a SS-VOD billet. ${ }^{10)}$ In comparison with $25 \% \mathrm{Cr}$ steel level, both values of $[\mathrm{C}]+[\mathrm{N}]$ and $[\mathrm{C}]+[\mathrm{O}]+[\mathrm{N}]$ by $\mathrm{EB}$ melting process were less than $1 / 2$ compared to those by the other conventional process, and the results of this work indicated much cleaner steel than that obtained by VIM or SS-VOD processes. In EB melting process, pressure level of the EB melting chamber is less than $1 / 100$ compared to that achieved by the conventional process and the local high temperature irradiated by electron beam is attained, so the reductions of carbon and nitrogen contents are made possible. In addition, the reduction of oxygen content is possible without addition of strong deoxidizer such as aluminum, magnesium and calcium, in addition, EB melting is possible without using refractories. This melting technique is also supposed to be advantageous for removal of inclusions.

In order to assess the effects of EB melting on product characteristicis, the pitting corrosion tests of sheets made by hot rolling and cold rolling were performed. The relation betwen testing temperature and corrosion speed of EBM material is shown in Fig. 16, in compared to that of VIM material. The corrosion rate was drastically reduced by the improved cleanliness achieved through EB melting. In addition, it was confirmed that the ductile-brittle transition temperature was decreased from room temperature to $-100^{\circ} \mathrm{C}$ by charpy impact testing of $25 \% \mathrm{Cr}$ alloy. Through EB melting, the toughness of the ferritic phase was improved by decreasing the concentration of interstitial component such as carbon and nitrogen.

As described above, drastic purification of gaseous elements such as carbon, oxygen and nitrogen was possible to attain by EB melting process, and improvements of corrosion resistance and mechanical properties were confirmed. Application of this process to various fields is expected in the future.

\section{Conclusion}

Experiments by rod melting technique with one EB gun were performed in order to determine quantitatively the evaporation of alloying elements and the behaviors of high purification reaction of carbon, oxygen and nitrogen in stainless steels and high chromium steel. The metallurgical effects of EB melting were studied with the following results:

(1) Evaporation reaction of alloying elements during EB melting could be expressed by equation of the first order reaction, and rate of reaction was supposed to be rate-controlled by evaporation reaction in metal-gas interface.

(2) Evaporation losses of alloying elements having higher vapor pressures (i.e. $\mathrm{Mn}>\mathrm{Cu}>\mathrm{Cr}>$ ) were large. Evaporation rate of elements was proportional to the square root of melting energy as expressed by dividing EB power by the melting speed of the feeding material. By the application of this relation, composition control of EB melted ingot was made possible through adjustment of chemical composition of raw material and controlling of melting energy.

(3) Decarburization and deoxidation reactions were promoted by $\mathrm{CO}$ reaction. The amounts of carbon and oxygen in EB melting ingots could be reduced by using an $[\mathrm{O}] /[\mathrm{C}]$ ratio of $1.25 / 1$ in raw materials. Higher input energy increased the level of denitrization and decarburization. Using EB melting process, it was possible to obtain $25 \% \mathrm{Cr}$ steel containing less than $50 \mathrm{ppm}$ total $[\mathrm{C}]+[\mathrm{O}]+[\mathrm{N}]$.

The toughness and corrosion resistance of strip sheets produced by hot rolling, cold rolling and annealing were greatly improved by the effects of decarburization, deoxidation and denitrization during EB melting. 
ISIJ International, Vol. 32 (1992), No. 5

\section{REFERENCES}

1) R. Bakish: J. Met ., (1987), No. 7, 27.

2) H. Harker and C. Entrekin: Proc. 1986 Int. Conf. on Titanium Products and Applications, Titanium Dep. Assoc., (1986), 939.

3) A. Mitchell and K. Takagi: Proc. 1984 Vac. Metall. Conf. Spec. Metals Melting Process, Iron Steel Soc., London, (1985), 55.

4) F. Kawaguchi, K. Moriya, M. Okamura, S. Koyama and K. Narita: Proc. 4th Int. Conf. Vacuum Metallurgy, Iron Steel Inst. Jpn., Tokyo, Section 2, (1974), 135.
5) Y. Nakamura, T. Mukai, M. Kuwabara and K. Arihara: Tetsu-to-Hagané, 63 (1977), 2246.

6) R. G. Ward: JISI, 201 (1963), 11.

7) K. Ono and J. Moriyama: Metall. Trans., 13B (1982), 241.

8) Steelmaking Data Source Book, ed. by 19th Comm. (Steelmaking), Jpn. Soc. Promotion of Sci., Gordon \& Breach, London, (1987).

9) T. Fuwa and S. Banya: Tetsu-to-Hagané, 51 (1965), 1843.

10) Y. Oguchi, H. Kaito, T. Suzuki, T. Emi, T. Murai, S. Miyazaki, S. Iwaoka and S. Yano: Kawasaki Steel Giho, 12 (1980), 561. 